\title{
Effects of baffle length on turbulent flows generated in stirred vessels
}

Research article

\author{
Meriem Ammar *, Zied Driss ${ }^{\dagger}$, Wajdi Chtourou, Mohamed S. Abid \\ National School of Engineers of Sfax (ENIS), \\ Laboratory of Electro-Mechanic Systems (LASEM), \\ University of Sfax, B.P. 1173, km1173, km 3.5 Soukra, 3038 Sfax, TUNISIA
}

\section{Received 11 January 2011 ; accepted 2 May 2011}

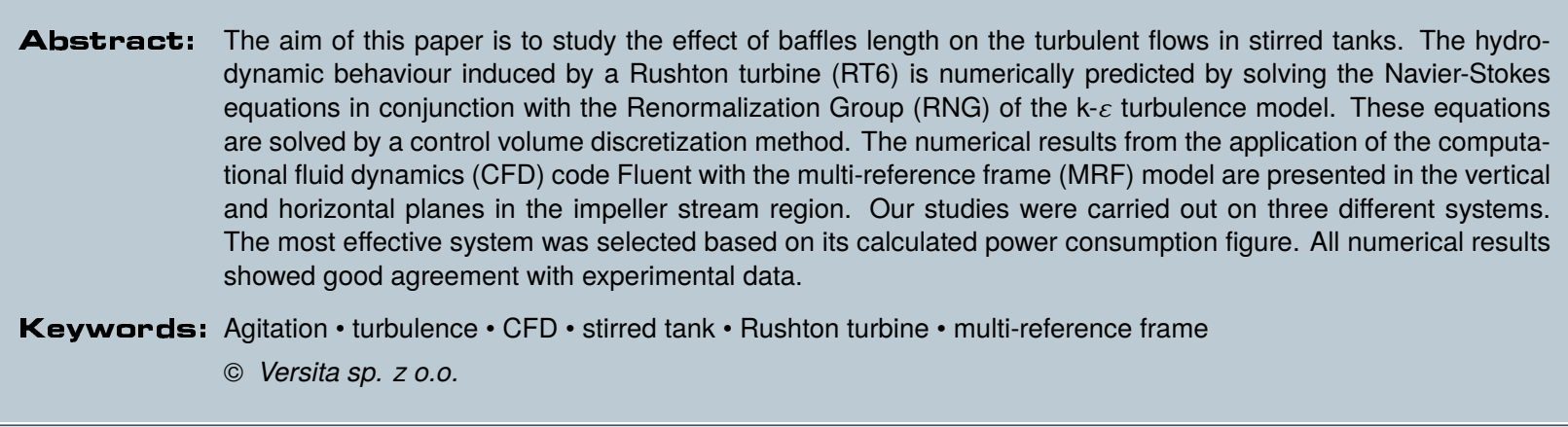

\section{Introduction}

Stirred vessels are extensively used in mineral, metallurgical and chemical process industries to perform a variety of operations such as homogenization, crystallization, gas dispersion, mechanical flotation, polymerization, and heat transfer. In the majority of cases, the flow field in baffled stirred vessels is highly turbulent and hence three-dimensional, complex, and chaotic in nature. During the last years, there have been continuous efforts on understanding these flows using both sophisticated experimental and computational fluid dynamics tools $[1,2]$. The

*E-mail: ammar.meriem@gmail.com,

Tel.: + 21674274 409; Fax: + 21674275595

${ }^{\dagger}$ E-mail: zied.driss@enis.rnu.tn study of turbulent flow and computation of its properties in a stirred vessel is a considerable challenge when using existing turbulence models. Factors contributing to this difficulty are the non-isotropic nature of flow in a stirred vessel, the complex geometry of rotating impellers and the large disparity in geometric scales [3]. The existence of baffles also increases the complexity of the flow field $[4,5]$. Analyzing the turbulent flow pattern and its properties in stirred vessels may be beneficial for equipment design, process scale-up, energy conservation and product quality control. Existing methods used for design of stirred vessels are based on experimental techniques. These methods give information about the flow pattern, the mixing mechanism, and the flow homogeneity of stirred tanks, all of which are parameters which influence the quality of the mixing process. Furthermore, because of equipment limitations, the unsteady nature of 
turbulent flows, the complexity of impeller blade geometry, and the relative motion among fluid elements, the acquisition of experimental data from most flow fields is usually expensive. The use of CFD for simulation of turbulent flow in stirred vessels can generate useful data to study flow behavior, circulation patterns, vortex structures, and Reynolds stresses.

Transport turbulence models of the averaged NavierStokes equations are the basis of most CFD simulations which has been reviewed by many investigators, such as Rodi [6] and Markatos [7]. The study of turbulent flow fields and their properties in stirred tanks has been the subject of numerous theoretical and numerical investigations. For example, Li et al. [8] studied the liquid drop impact on solid surfaces with application to water drop erosion on turbine blades by nonlinear wave modeling of one-dimensional impact. Harris et al. [9] applied both experimental and numerical methods to predict flow fields in baffled stirred tank reactors using time-dependent sliding mesh techniques. It was clearly shown that the comparison between the experimental findings and the numerical predictions was generally satisfactory, especially in regions far away from the impeller. Brucato et al. [10] used three alternative modeling approaches: the multi reference frame (MRF) method, the inner-outer (IO) iterative procedure and the sliding-grid (SG) method. These authors simulated flow fields in a baffled mixing tank stirred by a radial impeller and compared their simulation results with experimental data. They observed that results obtained by the SG approach gave the best agreement with the experimental data. Deglon et al. [11] investigated the effect of grid resolution and discretization scheme on the CFD simulation of fluid flow in a baffled mixing tank stirred by a Rushton turbine using the MRF impeller rotation model and the standard $k-\varepsilon$ turbulence model. On the other hand, Aubin et al. [12] focused on the effects of the numerical models such as the SM model and the MRF model, the discretization schemes, the grid scaling and the turbulence model, on the modeling accuracy of the turbulent flows generated by a sixpitched blade turbine (PBT6) in baffled stirred vessels. Moreover, Kchaou et al. [13] compared the effect of the flat-blade turbine with $45^{\circ}$ and $-45^{\circ}$ pitched blade turbines in turbulent flows.

Driss et al. [14] also studied the effects of the pitched blade turbine design. They considered three inclineangles, namely: $45^{\circ}, 60^{\circ}$ and $75^{\circ}$. Murthy et al. [15], on the other hand, studied five-impeller designs, namely disc turbines with several pitched blades, down flow turbine impellers with varying blade angles, and hydrofoil impellers. In that work, the tank was fully baffled, and the flow regime was turbulent. The authors' objective was to carry out a detailed investigation of the predictive capabilities of the various turbulence models, i.e. the standard $k-\varepsilon$ model, the Reynolds stress model (RSM), and the large Eddy simulations (LES) framework. Similarly, Vakili et al. [16] studied the effect of different geometric parameters in the stirred vessels with two-blade impellers. They employed the steady-state MRF approach and the standard k- $\varepsilon$ turbulence model in their parametric study. Moreover, Delafosse et al. [17] assessed the ability of computational fluid dynamics (CFD) to represent the trailing vortices and their relationship with turbulence properties. To that end, two simulation-based investigations were conducted: an unsteady Reynolds-averaged Navier-Stokes (URANS) simulation and a Large Eddy Simulation (LES).

In recent years, there has been continued interest in the study of power consumption for different impeller and tank geometries. For example, Kamienski [18], Saito et al. [19] and Ibrahim et al. [20] determined power characteristics for new types of high speed impellers. Power consumption data for low-speed impeller anchors, ribbons, helical screws, and gate agitators were presented in references [21-28]. Problems arising from the dependency on the scale of the input power within the agitated vessels were analyzed in references $[30,31]$. On the other hand, power consumption in agitated vessels equipped with short baffles was investigated by Strek et al. [29]. These investigations were performed for several impellers. Nevertheless, studies that focus on other types of agitators still lack in the field., The work of Iranshahi et al. [32],who studied the influence of baffles on the power number for a Maxblend turbine, however, is noteworthy. The authors showed that the power number for a baffled tank was higher than that of an unbaffled tank. Several other resesearchers also considered these matters. For example, Costes [33] used a Rushton turbine and compared the fields of the average velocities obtained by the laser Doppler velocimetry (LDV) method in the plane of the baffles and the median plane. Moreover, Nagata [34] proposed a generalized formulation of the power number that reflects the different geometrical parameters. Karcz et al. [35], on the other hand, studied the length of the baffles in a stirred tank equipped with different types of turbines. Specifically, they studied the case of a Rushton turbine, a Smith turbine, a pitched blade turbine, and a propeller. Moreover, Kresta et al. [36] studied the precipitation theory (along with experimental work) using a multi-mechanism model. Bhattacharya and Kresta [37] focused the effect of the submerged feed pipe position to the PBTU turbine in the dispersion of the air bubbles. Bhattacharya et al. [38] presented the impeller submergence, impeller diameter, baffle geometry and the physical properties of the fluid on the power number $N_{p}$ for an up-pumping turbine (PBTU) and down-pumping turbine (PBTD). Ciafalo et al. [39] studied the hydrodynamic structure in the closed and free surface unbaffled tank 


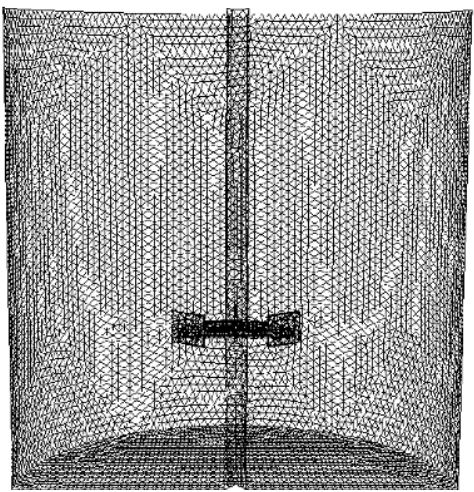

(a) Unbaffled tank

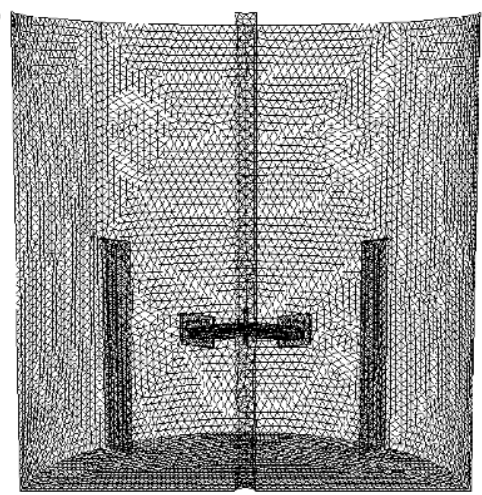

(b) Half-baffled tank

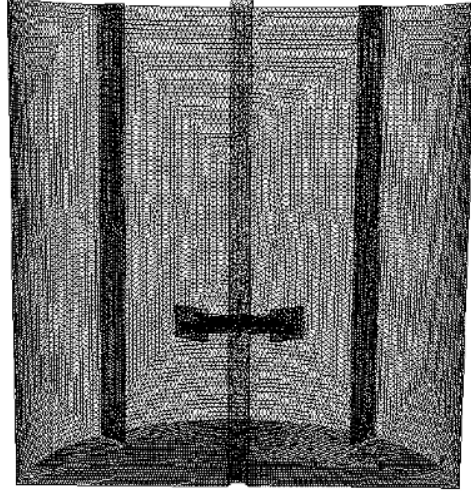

(c) Baffled tank

Figure 1. Stirred vessel configurations.

and the profiles of the central vortex developed in the tank with a free surface. Rice et al. [40] investigated the viscous fluid to understand the fluid dynamic characteristics generated with a Rushton turbine for the low Reynolds number. Yeoh et al. [41] compared the LES and the Reynolds Averaged Navier-Stokes (RANS) methods to predict the hydrodynamic structure in the stirred vessel equipped with a Rushton turbine. Moreover, Hartmann et al. [42] compared the LES and the RANS methods with the Laser Doppler Anemometry (LDA) experimental technique in the baffled stirred tank equipped with a Rushton turbine. Micale et al. [43-45] predicted the distribution of solid particles in the turbulent liquid flow of an agitated vessel with a Rushton turbine. They presented the assessment of the mass of suspended solid particles in stirred vessels using the pressure gauge technique. In addition, Micale et al. employed the Eulerian-Eulerian approach with the sliding grid algorithm and an an experimental technique to predict the suspension of a solid particle within a stirred vessel equipped with a Rushton turbine.

In this paper, we investigate three different geometrical configurations; our work addresses the lack of numerical results that predict the effect of baffle length on the hydrodynamic structure of the turbulent fluid flow. The first construct that we consider is a cylindrical unbaffled tank, the second, a half baffled tank, and the third, a fully baffled tank. Such a study is of great importance since it allows the calculation of the various parameters that characterize the local flow, and furthermore, it provides reliable information on the performance of various modalities of mechanical agitation. The distribution of the mean velocity and the turbulent characteristics are presented in different planes containing the turbine. In addition, the power required to drive an electromotor coupled with the shaft of the agitated vessel has been calculated on the basis of the power characteristics which are determined for a given type of impeller. The numerical results present the effect of baffle length $t$ on the local and global flow characteristics.

\section{Sitrred Vessel Configuration}

The first configuration we considered is that of a cylindrical tank equipped with a Rushton turbine (Figure 1a). The second configuration is a half baffled tank (Figure 1b) and the third is a fully baffled tank (Figure 1c). The height of the cylindrical tank is equal to its diameter $(\mathrm{D}=\mathrm{H})$, and the baffle thickness is defined by $w=H / 10$. The Rushton turbine is placed in the axial position corresponding to $\mathrm{z}=\mathrm{H} / 3$, and has diameter $\mathrm{d}=\mathrm{D} / 3$. The third geometry we considered is similar to that discussed in reference [46] byWu et al..

\section{Numerical Model}

The CFD code "Fluent" is used for the numerical simulation of the hydrodynamic structure of the turbulent flows present within the mixing vessel. This code is based on solving Navier-Stokes equation with a finite volume discretization method described in detail by Patankar [47]. This technique consists of dividing the computational domain into elementary volumes around each node of the grid in order to ensure the flow's continuity between nodes. In all cases, we used tetrahedral elements for meshing. A total grid size of $214200(r \times \theta \times z$ : $25 \times 168 \times 51)$ was used for the full domain of the tank. The impeller region $66576(r \times \theta \times z$ : $20 \times 84 \times 22)$ was meshed with $31 \%$ of 
Table 1. Constants of the $k-\varepsilon$ RNG model.

\begin{tabular}{ccccc}
\hline $\mathrm{C}_{\mu}$ & $\mathrm{C}_{1 \varepsilon}$ & $\mathrm{C}_{2 \varepsilon}$ & $\sigma_{k}$ & $\sigma_{\varepsilon}$ \\
\hline \hline 0.0845 & 1.42 & 1.68 & 0.07179 & 1.3 \\
\hline
\end{tabular}

the total grid size used for the full tank in order to resolve the steep gradients in the impeller region. As for the temporal discretization, the implicit formulation was adopted. The transport equation was integrated over the control volume. The SIMPLE algorithm was used for pressure velocity coupling. To model the geometry of the impeller exactly, a 3D simulation was performed. The MRF approach served to incorporate in the model the motion of the impeller within the stirred vessel as recommended by Deglon et al. [11], Vakili et al. [16], Luo et al. [48], Armenante et al. [49], and Akiti et al. [50].

\subsection{Power Consumption}

Knowing the power consumption is very important for the choice of the engine. The power consumption depends on all parameters characterizing the external geometry of the tank, the geometry of the agitator, the flow regime, and the rotating speed of the mobile. The power number $\mathrm{N}_{p}$ is a metric that allows the extrapolation of the calculated power when the diameter of the agitator $d$ and its rotational speed $\mathrm{N}$ change. The power number is defined as follows:

$$
N_{P}=\frac{P}{\rho N^{3} d^{5}}
$$

where $\mathrm{P}$ is the power consumption of the agitator system.

$$
P=2 \pi N C
$$

$C$ is the torque of the agitator system.

\subsection{Boundary Conditions}

The first configuration is the unbaffled stirred tank equipped with a six-blade Rushton turbine (RT6). The computational domain is reduced to $60^{\circ}$, which includes only one blade, while the other two configurations contain four baffles placed at the lateral surface and are equipped with a six-blade Rushton turbine (RT6). Thus, the computational domain is reduced to $180^{\circ}$, which includes two baffles and three blades. At the two frontal planes defined by angular positions $\theta=-90^{\circ}$ and $\theta=90^{\circ}$, periodic conditions are imposed on all properties ensuring the continuity of the computational domain in the angular direction.

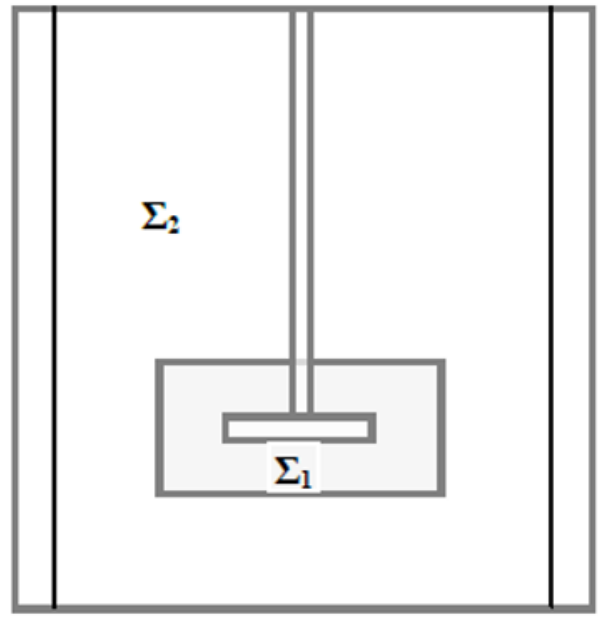

Figure 2. Cylindrical tank with an MRF boundary surrounding the impeller.

The multiple reference frames (MRF) approach allows for the modeling of stirred tanks and tanks with other internal components. A rotating frame $\left(\omega_{1}\right)$ is used for the region containing the rotating components while a stationary frame $\left(\omega_{2}\right)$ is used for regions that are stationary (Figure 2). In the rotating frame containing an impeller, the impeller is at rest. Conversely, in the stationary frame containing the tank walls and baffles, the walls and baffles are at rest. The grid used for MRF solution must have a perfect surface of revolution surrounding each rotating frame. The momentum equations inside the rotating frame are solved in the frame of the enclosed impeller while those outside the rotating frame are solved in the stationary frame. A steady transfer of information is made at the MRF interface as the solution progresses. While the solution of the flow field in the rotating frame in the region surrounding the impeller imparts the impeller rotation to the region outside this frame, the impeller is taken to be stationary during this type of calculation.

\section{Numerical Model}

\subsection{Convergence Criteria}

If the algebraic form of a conservation equation in any control volume momentum equation could be solved exactly, it would be written as follows:

$$
A_{P} \Phi_{P}-\sum_{i} A_{i} \Phi_{i}=0
$$

since the solution of each equation at any step in an it- 
erative calculation is based on inexact information. Originating from initially guessed values and refined through repeated iterations, the right hand side of the above equation is always non-zero. This non-zero value represents the residual in the solution of the equation in the control volume.

$$
R_{P}=A_{P} \Phi_{P}-\sum_{i} A_{i} \Phi_{i}
$$

The total residual is the sum over all cells in the computational domain of the residuals in each cell.

$$
R=\sum_{p} R_{P}
$$

Since the total residual $\mathrm{R}$ is defined in this manner, it is dependent on the magnitude of the variable being solved. In that case, it is customary to either normalize or scale the total residual to gauge its changing value during the solution process. While normalization and scaling can be done in a number of ways, it is the change in the normalized or scaled residuals that is important in evaluating the rate and level of convergence of the solution. A typical simulation is considered converged when the residual mass and other quantities characterizing the flow such as the three velocity components, the turbulent kinetic energy, and the dissipation rate all fall below $10^{-6}$.

\section{Numerical Results}

Using the steady-state MRF approach, the distribution of the velocity components and the turbulence characteristics have been introduced in the vertical and horizontal plane containing the blade. The turbulent flow is defined by a Reynolds number $\operatorname{Re}=40000$ and impeller speed $N=250$ rpm.

\subsection{Distribution of the Mean Velocity in the $\mathrm{r}=\theta$ Plane}

Figure 3 shows the distribution of the mean velocity in the $r-\theta$ plane containing the turbine. In all three systems, the wake of the maximum values of the mean velocity is extended in the field swept by the impeller upstream of the blades.We noted that the presence of the baffle decreased the mean velocity within the fluid. Outside the area swept by the turbine, the mean velocity decreased and vanished abruptly in the proximity of the lateral side of the tank. Especially in baffled stirred vessels, we found that the field of low velocity was near the side walls and around the baffles. Consequently, we deduced that the presence of baffles in the side wall of the tank decreased the average velocity in the vicinity of the sidewall.

\subsection{Distribution of the Mean Velocity in the r-z Plane}

Figure 4 shows the distribution of the mean velocity in the $r-z$ plane containing the blades. We observed the appearance of a strong centrifugal flow from the blades that reached up to the sidewall of the tank placed in front of the radial jet. In a cylindrical tank, the flow generated by the rotation of the Rushton turbine is very low. The radial jet does not reach the lateral walls. As a result, the presence of the baffles intensified the radial jet which reached the lateral surface which, in turn, caused two axial jets, one up and one down. In the baffled stirred tank, the axial jet was found to be the most significant. This upward jet brought up the recirculation loop extended in the upper area of the tank thereby feeding back to the turbine. We noted a great similarity in the lower area of the second configuration and that of the third configuration, presumably because these two systems are baffled in the lower zone. Moreover, we noticed a recirculation zone which arose to power the Rushton turbine. But in the upper zone, the upward axial jet dropped sharply in the absence of the baffles in the top of the tank. The recirculation loop in the upper zone was less extensive. Thus, we concluded that the use of baffles on the height of the tank increases the axial jets on either side of the turbine, and furthermore, promotes the circulation of the fluid throughout the volume of the tank.

\subsection{Axial Profile of the Radial Velocity}

Figure 5 presents the axial profiles of the radial component of the velocity in these three configurations, already studied in the previous paragraph. We found that the radial component was maximum in the discharge area of the turbine and that it decreased gradually away from this area. The radial component of the velocity was highest in the baffled tanks. On both sides of the area swept by the turbine, we noted a significant decrease of this component due to the baffles, especially in the lower area of the tank. The negative values of this component indicate that the fluid flow was drawn through the movement of the impeller. Especially in the upper zone, it was found that the radial velocity was very low in all the tanks. This proves that the baffles do not have much effect on the radial component of the velocity at the top of the tank. 


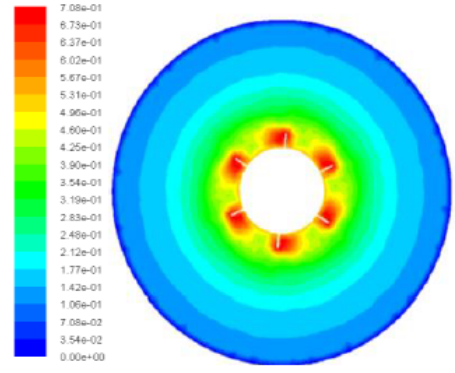

(a) Unbaffled tank

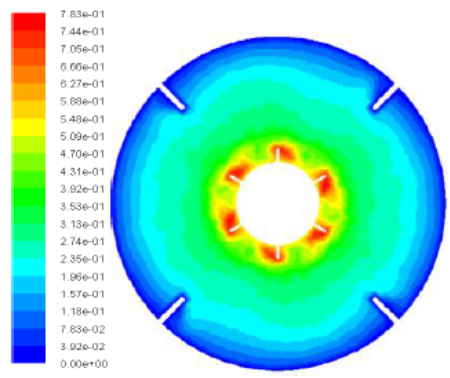

(b) Half-baffled tank

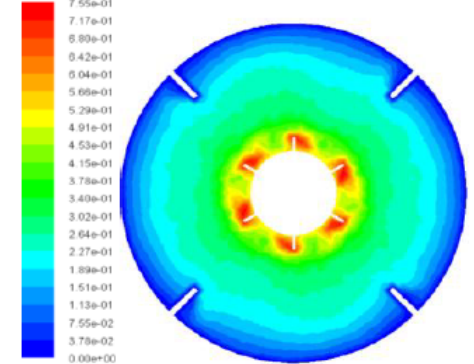

(c) Baffled tank

Figure 3. Distribution of the mean velocity in the $r-\Theta$ plane.

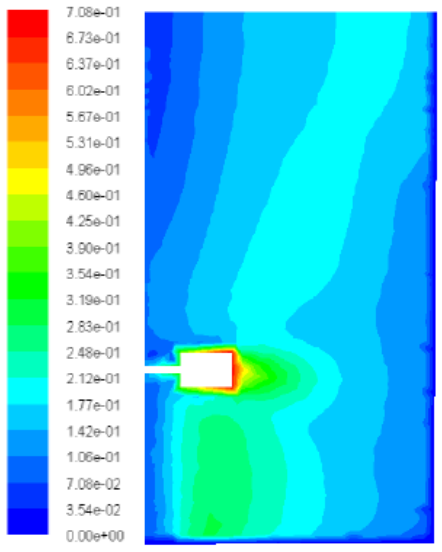

(a) Unbaffled tank

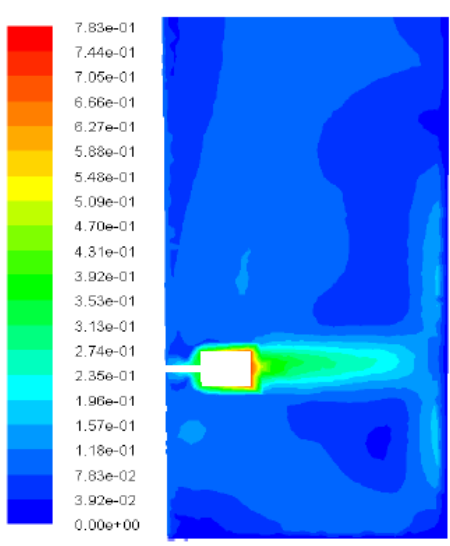

(b) Half-baffled tank

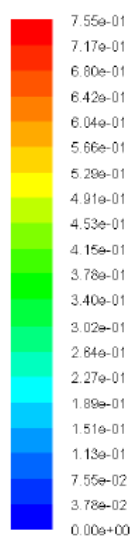

$000+0$

(c) Baffled tank

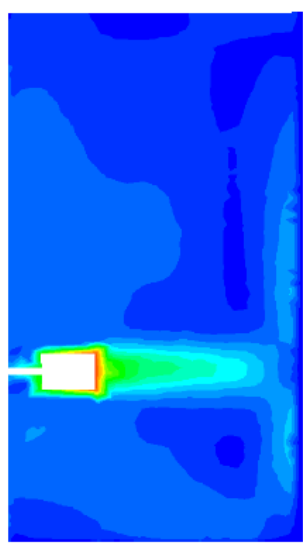

Figure 4. Distribution of the mean velocity in the r-z plane.

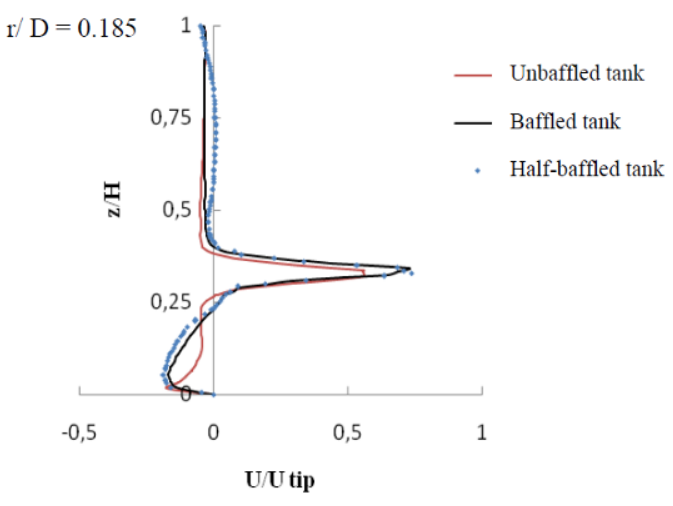

Figure 5. Axial profile of the radial velocity.

\subsection{Axial Profile of the Tangential Velocity}

Figure 6 shows the axial profiles of the tangential component of the velocity on the entire height of the tank. These profiles show three areas of study. In the discharge of the turbine between $\mathrm{z} / \mathrm{H}=0.26$ and $\mathrm{z} / \mathrm{H}=0.4$, we found that the tangential component was maximum in the three systems. On both sides of the turbine, we noted the presence of two recirculation zones. At the bottom of the tank, the movement of the fluid was more intense in the unbaffled tank. Moreover, the presence of the baffles in the lower zone caused a decrease in the tangential component. Therefore, the negative values of this component showed the presence of the intense circulation near the agitator axis. In addition, near the top of the baffled tank, the tangential velocity component decreased suddenly, a situation which prevents the formation of a vortex around the agitator shaft. In the unbaffled tank, the tangential component of the velocity dominated the other components of 


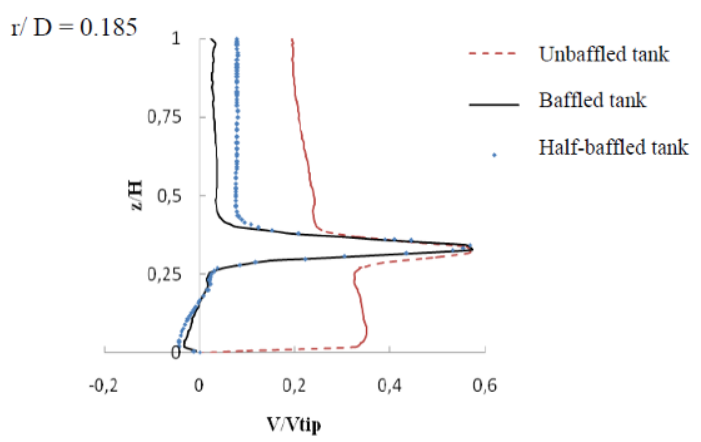

Figure 6. Axial profile of the tangential velocity.

the velocity, and created a purely circular motion of the fluid within the tank. This is evidence that the use of baffles along the length of the tank is critical; the baffles decrease the tangential component and prevents vortices from occurring.

\subsection{Axial Profile of the Axial Velocity}

Figure 7 shows the axial profiles of the axial component of the velocity on the height of the tank. These profiles show great similarity. On both sides of the turbine, we noted the presence of the two recirculation zones. At the bottom of the tank, the motion of the fluid was more intense in the baffled tank and the half-baffled tank. In addition, at the top of the tank, the presence of the baffles increased the axial jet upward. Similarly, the negative values in the upper area of the tank, behind the recirculation of the fluid, explain the flow drawn at the shaft to power the turbine. Consequently, we concluded that the use of baffles on the height of the tank amplified the axial jets that originate at the lateral surface. As a result, the presence of baffles allows an increase in the circulation of the fluid throughout the tank's volume, which in turn, causes a uniform degree of homogeneity across the field.

\subsection{Distribution of the Turbulent Kinetic En- ergy in the $r-\theta$ Plane}

Figure 8 shows the distribution of the turbulent kinetic energy in the $r-\theta$ plane containing the turbine. In general, our study revealed the existence of the wake area characterized by the maximum of the turbulent kinetic energy which is localized around the mechanics source. The maximum value of the turbulent kinetic energy was reached in the half baffled tank.

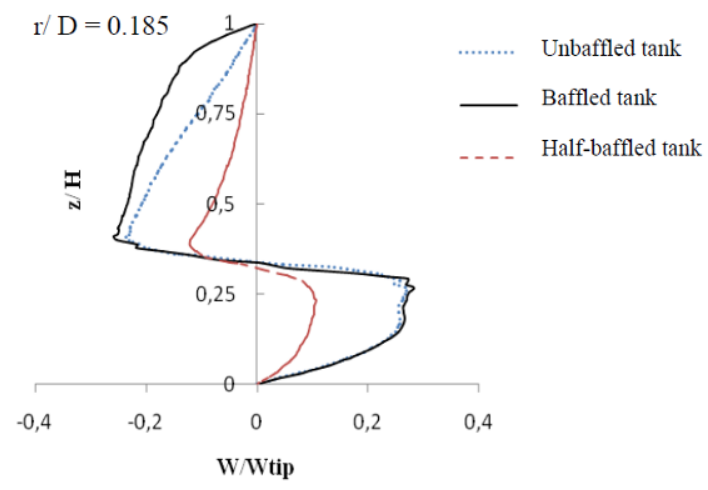

Figure 7. Axial profile of the axial velocity.

\subsection{Axial Profile of the Turbulent Kinetic Energy}

Figure 9 illustrates the axial profiles of the turbulent kinetic energy on the entire height of the tank. Three study areas emerged from these profiles. Particularly, we observed that in the lower part of the tank, the presence of the baffles (in both the baffled tank and the half-baffled tank) allowed the superposition of the turbulent kinetic energy profiles. In the half baffled tank, the turbulent kinetic energy was maximum in the discharge area of the turbine between $\mathrm{z} / \mathrm{H}=0.26$ and $\mathrm{z} / \mathrm{H}=0.4$ whereas, in the baffled tank, the baffles in the upper parts of the tank decreased the turbulent kinetic energy. Thus, we concluded that the baffles generally lowered the turbulent kinetic energy.

\subsection{Distribution of the Dissipation Rate of the Turbulent Kinetic Energy in the $r-\theta$ Plane}

Figure 10 shows the distribution of the dissipation rate of the turbulent kinetic energy in the $r-\theta$ plane. This plane is defined at the median of the blade. We found that the area of the maximum values was located in the wake developed at the end of the turbine blades. These zones showed that the dissipation rate of the turbulent kinetic energy reached a very important value in the turbine. This observation is best explained by the transformation of the turbulent kinetic energy into heat through viscous friction. Nevertheless, the dissipation rate of the turbulent kinetic energy remained very low outside the area swept by the blades.

The unbaffled vessel showed the highest energy dissipation rate (Figure 9a). Conversely, the dissipation figure decreased for the half-baffled tank, and it was even lower for the baffled tank. We thus concluded that the pres- 


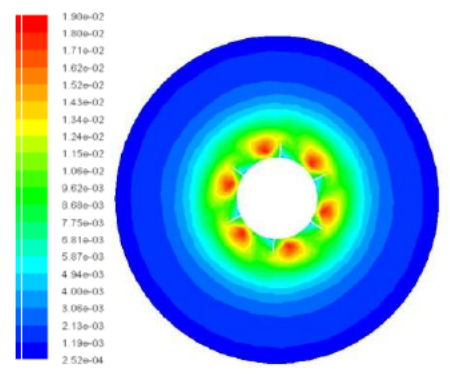

(a) Unbaffled tank

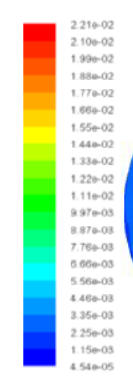

(b) Half-baffled tank

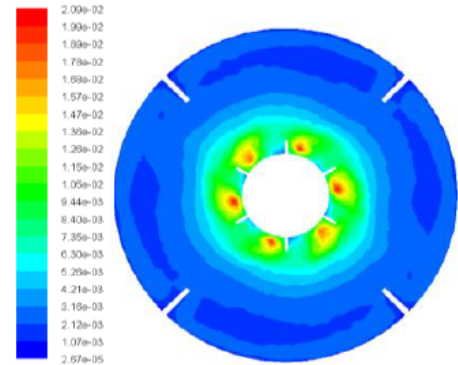

(c) Baffled tank

Figure 8. Distribution of the turbulent kinetic energy in the $r-\theta$ plane.

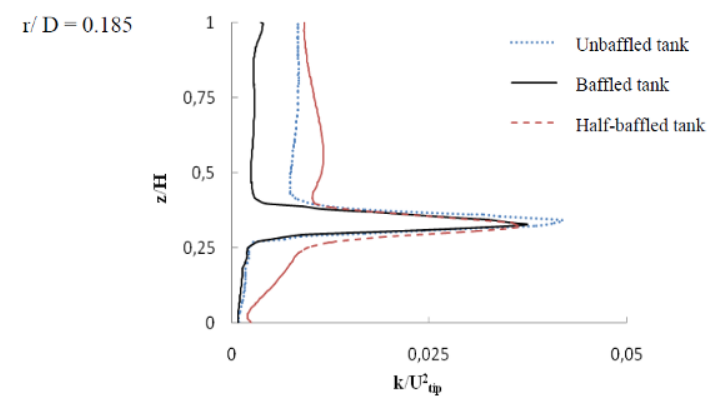

Figure 9. Axial profile of the turbulent kinetic energy.

ence of the baffles had no effect on the distribution of the dissipation rate of turbulent kinetic energy in the tank.

\subsection{Distribution of the Turbulent Viscosity in the $r-\theta$ Plane}

Figure 11 shows the distribution of the turbulent viscosity in the $r-\theta$ plane defined in the median of the blade. In the unbaffled tank, the turbulent viscosity was maximal in the area swept by the turbine. Especially, it was noted that a wake, characterized by the high values of the turbulent viscosity $v t$, was developed downstream of the blade. Therefore, in the changeover of the blades, the turbulent viscosity vanished abruptly. In proximity of the lateral surface, the turbulent viscosity dropped rapidly. With the tank baffles, we noted that a wake characterized by low values, was developed around the baffles. We thus deduced that the turbulent viscosity was very low in the baffled tank (Figure 11c).

\subsection{Distribution of the Turbulent Viscosity in the r-z Plane}

Figure 12 shows the distribution of the turbulent viscosity in the $r-z$ plane containing the blade. Comparing the three configurations, we found that the region of highest viscosity was located in the intense circulating flow developed in the upper area of each tank. Furthremore, for the unbaffled tank, the maximum value of turbulent viscosity was reached in the upper zone. However, it was very weak near the turbine and it decreased more and more in lower areas of the tank. The lowest viscosity values were in the immediate vicinity of the solid walls and outside the field swept by the turbine. At the bottom of the tank, the fluid circulation was very low because of the small gap between the turbine and the bottom surface.. For the baffled tank, the turbulent viscosity was very low. In addition, we noted the existence of two wakes in the upper area of the tank and in the recirculation jet, both located at the bottom of the tank.

\subsection{Power Characteristics}

Figure 13 illustrates the variation of energy consumption as a function of the Reynolds number Re within a six-blade Rushton turbine placed, respectively, in the unbaffled tank, the half-baffled tank, and the baffled tank. We found that the energy dissipation within the fluid increased when there were baffles in the tank. For the Reynolds numbers between $10^{3}<\operatorname{Re}<10^{4}$, the energy dissipation in the three systems was very similar. In the fully turbulent regime, i. e. for Reynolds number between $10^{4}<\operatorname{Re}<10^{5}$, the baffled systems showed a much greater energy dissipation. Therefore, we concluded that the baffled tank was the best system because, overall, the presence of the baffles improved the quality of the mixture while this system dissipated slightly more energy than the other systems. 


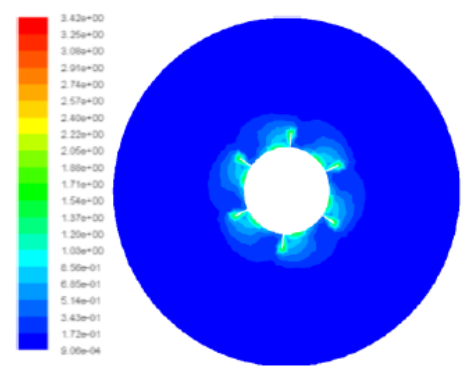

(a) Unbaffled tank

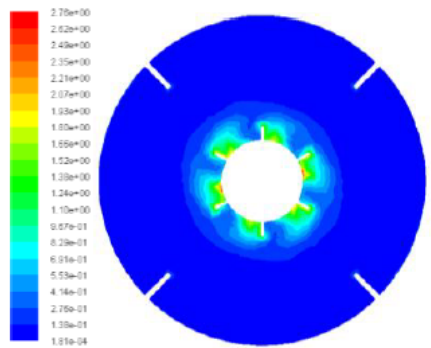

(b) Half-baffled tank

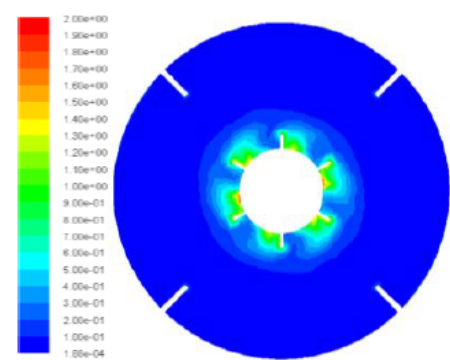

(c) Baffled tank

Figure 10. Distribution of the dissipation rate of the turbulent kinetic energy in the $\mathrm{r}-\theta$ plane.

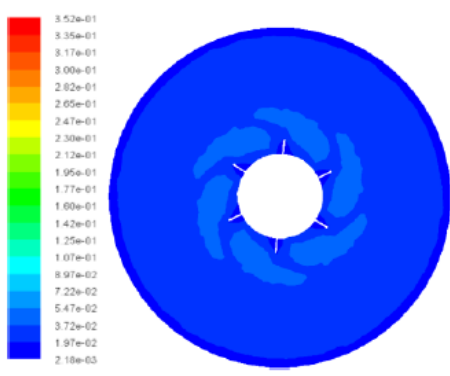

(a) Unbaffled tank

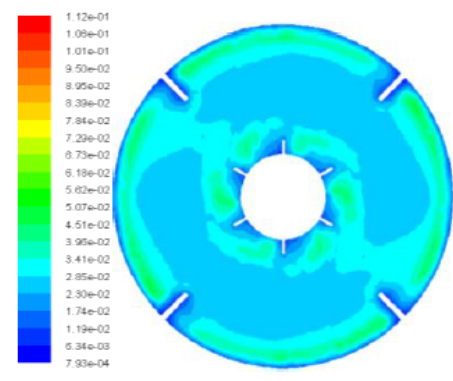

(b) Half-baffled tank
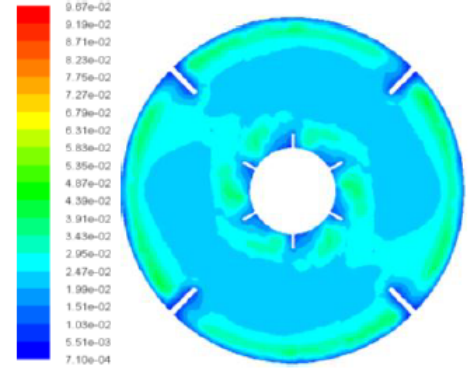

(c) Baffled tank

Figure 11. Distribution of the turbulent viscosity in the $r-\theta$ plane.

\section{Comparison with Experimental Results}

Figure 14 shows the axial profiles of the radial and tangential velocity components in the radial position defined by $r / D=0.185$ in the baffled stirred tank equipped with the Rushton turbine. The apparatus used in the experiment consisted of a stirred mixer and analysis tools that made use of LDV along with computer data acquisition software. The LDV system used was a standard one direction model by Defence Information Systems Agency (DISA), with coaxial optics operating in the dual-beam differential mode. The velocimeter was used to measure velocities in all three directions in all portions of the tank. The highest density of measurement points was near the impeller tip where the radial jet was formed. Corrections were made for the periodic non-turbulent velocity pulsations produced by the turbine blades. The turbulence intensity near the blade tips was reduced by about $10 \%$. The correction diminished rapidly away from the impeller. The tracking particles were 6-micron diameter polystyrene spheres. The length scales were measured by integrating autocorrelations, and subsequently, by multiplying by the average velocity. The experimental results found by Wu et al. [46] were superposed over an average error of $8 \%$. The good agreement between our experimental results and the numerical results confirmed the validity of the analytical methods proposed herein.

\section{Conclusion}

The results of the numerical studies presenting the effects baffles on the turbulent flow characteristics have been studied in the horizontal and vertical planes that contain the impeller. This paper discussed the effect of the baffle length on the power consumption for three systems. The power characteristics for the three agitator systems were obtained for the turbulent regime of the fluid flow. In these conditions, the power number depended strongly on the length of the baffle. Therefore, the presence of the baffles in the tank greatly improved the quality of the mixture. Moreover, the baffled tank was found to consume slightly more of the energy than the two other systems. Therefore, conclude that the baffled 


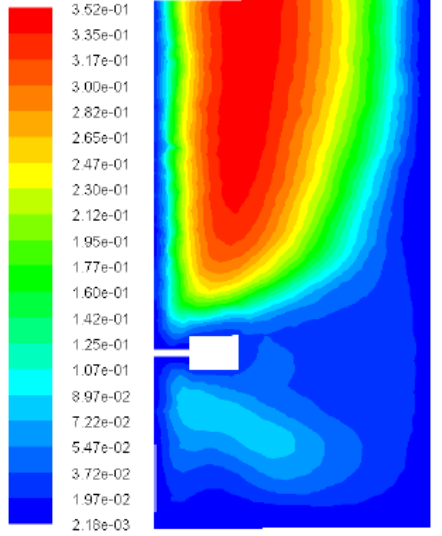

(a) Unbaffled tank

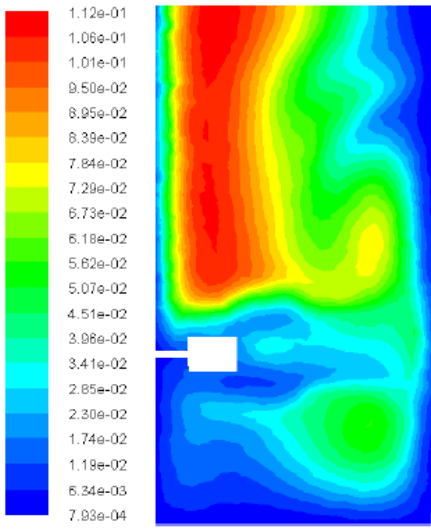

(b) Half-baffled tank

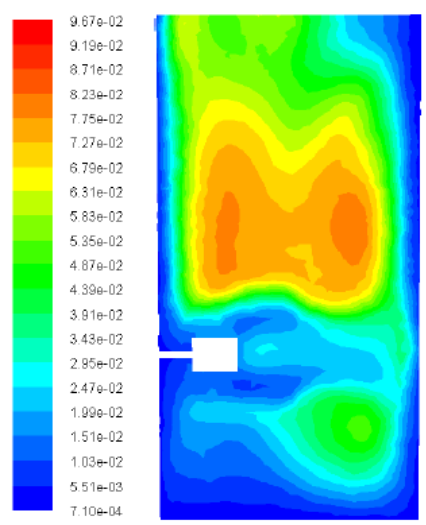

(c) Baffled tank

Figure 12. Distribution of the turbulent viscosity in the r-z plane.

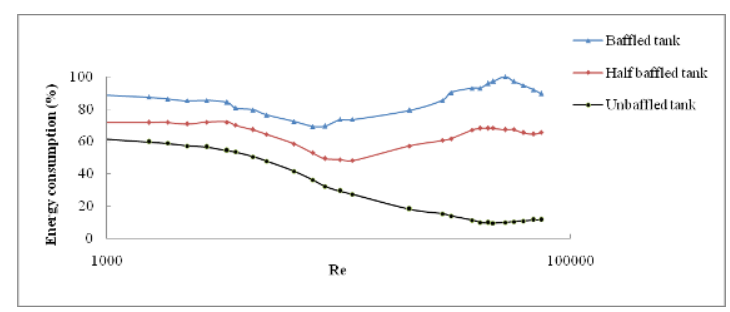

Figure 13. Evolution of the energy consumption (\%).

tank is the optimized geometrical system. Our future work will focus on the development of large Eddy simulations that will study several stirred tank configurations.

\section{Nomenclature}

$D$ : diameter of the tank $(m)$

$\mathrm{d}$ : diameter of the impeller $(\mathrm{m})$

$\mathrm{H}$ : height of the tank $(\mathrm{m})$

$\mathrm{w}$ : thickness of the baffles $(\mathrm{m})$

$N$ : rotating speed of the impeller $\left(\mathrm{s}^{-1}\right)$

$\mathrm{R}$ : radius of the tank $(\mathrm{m})$

$r$ : radial coordinate $(m)$

$z$ : position of the turbine relative of the bottom of the tank $(\mathrm{m})$

$\mathrm{P}$ : power $(\mathrm{W})$

\section{Greek Letters}

$v$ : kinetic viscosity of the fluid $\left(\mathrm{m}^{2} \cdot \mathrm{s}^{-1}\right)$

$\rho$ : density of fluid $\left(\mathrm{kg} \cdot \mathrm{m}^{-3}\right)$

$\mu$ : dynamic viscosity of the fluide (Pa.s)

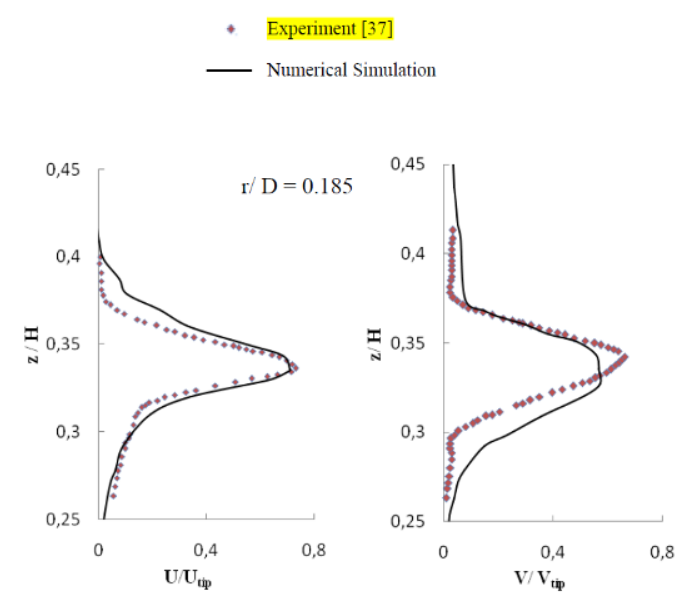

Figure 14. Axial profiles of the radial and the tangential component of the velocity.

Dimensionnels Numbers

$R e=\frac{\rho N d^{2}}{\mu_{P}}:$ Reynolds number

$N_{P}=\frac{{ }_{P}}{\rho N^{3} d^{5}}$ : Power number

\section{References}

[1] Tao L.N., Gupta S.D., Confined laminar jet mixing in a circulor channel with arbitrary entrance velocity distribution, acta mechanica., 1672, 15,1-19

[2] Datta N., Das S.K., Axially symmetrical jet mixing an incompressible dusty fluid, acta mechanica., 1985, 55, 111-122 
[3] Keck H., Sick M., Thity years of numerical flow simulation in hydrolic turbomachines, acta mechanima., 2008, 20, 211-229

[4] Tsay Y.L., Chang T.S.,Cheng J.C., Heat transfer enhancement of backward-facing step flow in a channel by using baffle installation on the channel wall, acta mechanica 2005,174, 63-76

[5] Sapountzakis E.J., Dourakopoulos J.A., Shear deformation effect in flexural torsional vibrations of beams by BEM. Acta mechanica., 2009, 203, 197-221

[6] Rodi W., Turbulence models and their applications in hydraulics a state of art reviews. International Association on Hydraulic Research, CityDelft, Netherlands., 1980

[7] Markatos N.C., The mathematical modeling of turbulent flows. Applied Mathematical Modeling, 1986, 10, 190-220

[8] Li N., Zhou Q., Chen X., Xu T., et al., Liquid drop impact on solid surface with application to water drop erosion on turbine blades, Part I: Nonlinear wave model and solution of one-dimensional impact. International Journal of Mechanical Sciences., 2008, 50, 1526-1542

[9] Harris C.K., Roekaerts D., Rosendal F.J.J., Buitendijk F.G.J., et al. Computational fluid dynamics for chemical reactor engineering. Chemical Engineering Science., 1996, 51, 1569-1594.

[10] Brucato A., Ciofalo M., Grisafi F., Micale G., Numerical prediction of flow fields in baffled stirred vessels: A comparison of alternative modelling approaches, Chemical Engineering Science., 1998, 53, 3653-3684

[11] Deglon D.A., Meyer C.J., CFD modeling of stirred tanks: Numerical considerations, Minerals Engineering., 2006, 19, 1059-1068

[12] Aubin J., Fletcher D., Xuereb C., Modelling turbulent flow in stirred tanks with CFD: the influence of the modelling approach, turbulence model and numerical schema, Experimental Thermal and Fluid Science., 2004, 28, 431-445

[13] Kchaou H., Driss Z., Bouzgarrou G., Chtourou W., et al. Numerical investigation of internal turbulent flow generated by a flat-blade turbine and a pitched-blade turbine in a vessel tank, International review of Mechanical Engineering (I.RE.M.E.), May 2008, 2, 3

[14] Driss Z., Bouzgarrou G., Chtourou W., Kchaou H., et al.,Computational studies of the pitched blade turbines design effect on the stirred tank flow characteristics, European Journal of Mechanics B/Fluids., 2010, 29, 236-245

[15] Murthy N.B., Joshi J.B., Assessment of standard k- $\varepsilon$ RSM and LES turbulent models in a baffled stirred agitated by various impeller designs, Chemical Engineering Science., 2008, 63, 5468-5495
[16] Vakili M.H., Nasir M., Esfaharry, CFD analus of turbulence in a baffled stirred tank, a three compartement model, Chem.Eng.Sci., 2009, 64, 351-362

[17] Delafosse A., Morchain J., Guiraud P., Liné A., Trailing vortices generated by a Rushton turbine : Assessment of URANS and large eddy simulation, Chemical Engineering Reasearch and Design., 2009, 87, 401-411

[18] Kamieński J., Mixing power of turbine-type impellers with divided, inclined blades, Intern. Chem. Eng., 1990, 30 (3), 517-525

[19] Saito F., Nienow A.W., Chatwin S., Moore J.T., Power, gas dispersion and homogenisation characteristics of SCABA SRGT and Rushton turbine impellers, J. Chem. Eng. Japan., 1992, 25 (3), 281-287

[20] Ibrahim S., Nienow A.W., Power curves and flow patterns for a range of impellers in Newtonian fluids 40BReB5_105, Chem. Eng. Res. Des., 1995, 73, Part A, 485-491

[21] Deak A., Havas G., Sawinsky J., The power requirements for anchor, ribbon and helical-screw agitators, Intern. Chem. Eng., 1985, 25 (3), 558-565

[22] Bertrand J., Couderc J.P., Evaluation of the power consumption in agitation of viscous Newtonian or pseudoplastic fluid by two-bladed, anchor or gate agitators, Chem. Eng. Res. Des., 1985, 63, 259-263

[23] Shamlou P. Ayazi, Edwards M.F., Power consumption of helical ribbon mixers in viscous Newtonian and non-Newtonian fluids, Chem. Eng. Sci., 1985, 40, 1773-1781

[24] Rieger F., Novak V., Havelkova D., The influence of the geometrical shape on the power requirement of ribbon impellers, Intern. Chem. Eng., 1988, 28 (2), 376-383

[25] Shamlou P. Ayazi, M.F. Edwards, Power consumption of anchor impellers in Newtonian and non-Newtonian liquids, Chem. Eng. Res. Des., 1989, 67, 537-543

[26] Maruko M., Kusumoto S., Power consumption characteristics of a lattice-type, twin-shaft, high-viscosity agitator, Intern. Chem. Eng., 1992, 32 (4),759-766

[27] Masiuk S., H. Lacki, F. Stręk, Power consumption and mixing times for liquid mixing in a ribbon mixer, Chem. Eng. J., 1992, 48, 135-140

[28] Bohme G., Stenger M., Consistent scale-up procedure for power consumption in agitated non-Newtonian fluids, Chem. Eng. Technol., 1988, 11, 199-205

[29] Stręk F., Mixing and Agitated Vessels, WNT, Warsaw, 1981 (in Polish)

[30] Bujalski W., Nienow A.W., Chatwin S., Cooke M., The dependency on scale of power numbers of Rushton disc turbines,Chem. Eng. Sci., 1987, 42, 317-326

[31] Geisler R.K., Buurman C., Mersmann A.B., Scale-up of the necessary power input in stirred vessels with suspension, Chem.Eng. J., 1993, 51, 29-39 
[32] Iranshahia A., Devalsa C., Henichea M., Fradettea L., et al. , Hydrodynamics characterization of the Maxblend impeller, Chem. Eng. Sci., 2007, 62, 36413653

[33] Costes J., Couderc J.P., Study by laser Doppler anemometry of the turbulent flow induced by a Rushton turbine in stirred tank: influence of the size of the units (Part I\&II), Chem.ing.Scien., 1988, 43(10), 2754-2772

[34] Nagata S., Mixing: principles and applications. John Wiley \& Sons: Halstead press, Japan, 1975

[35] Karcz J., Kamińska-Brzoska J., Experimental studies of the influence of the blade curvature of a disc turbine on power consumption, Inz; . Chem. i Proc., 1994, 15 (3) 371-378 (in Polish)

[36] Kresta S.M, Anthieren G.L, Parsiegla K., Mixing effects in silver halide precipitation linking theory with practice using a multi-mechanism model, Trans IChemE., september (2004), part(A), Chemical Engineering Research and design, 82(A9):1117-1136

[37] Bhattacharya S., Kresta S. M., Surface feed with minimum by-product formation for competitive reactions, Trans IChemE., September 2004, Part A, Chemical Engineering Research and Design, 82(A9): 11531160

[38] Bhattacharya S., Hebert D., Kresta S.M., Air entrainment in baffled stirred tanks, Trans IChemE., May 2007, Part A, Chemical Engineering Research and Design, 85 (A5) 654-664

[39] Ciofalo M., Brucato A., Grisafi F., Torracaciofalo N., Turbulent flow in closed and free-surface Unbaffled tanks stirred by radial impellers, Chemical Engineering Science., 1996, 51, 14, 3557- 3573

[40] Rice M., Hall J., Papadakis G., Yianneskis M., Investigation of laminar flowin a stirred vessel at low Reynolds numbers, Chemical Engineering Science., 2006, 61, 2762-2770
[41] Yeoh S. L., Papadakis G., Yianneskis M., numerical simulation of turbulent flow characteristics in a stirred vessel using the les and rans approaches with the sliding deforming mesh methodology, Chemical Engineering Research and Design, Trans IChemE., 2004, 82(A7) Part A, 834-848

[42] Hartmanna H., Derksena J.J., Montavonb C., Pearsonb J., et al., Assessment oflarge eddy and RANS stirred tank simulations by means of LDA, Chemical Engineering Science, 2004, 59, 2419-2432

[43] Micale G., Montante G., Grisafi F., Brucato A. et al., CFD simulation of particle distribution in stirred vessels, Institution of Chemical Engineers Trans IChemE., 2000, 78 Part A

[44] Micale G., Grisafi F., Brucato A., Assessment of particle suspension conditions in stirred vessels by means of pressure gauge technique, Institution of Chemical Engineers, Trans IChemE., 2002, 80 Part A

[45] Micale G., Grisafi F., Rizzuti L., Brucato A., CFD simulation of particle suspension height in stirred vessels, Chemical Engineering Research and Design, Trans IChemE., 2004, 82(A9) Part A, 1204-1213

[46] Wu H., Patterson, G.K., Laser-Doppler measurements of turbulent-flow parameters in a stirred mixer. Chemical Engineering Science., 1989, 44, 2207-2221

[47] Patankar S.V., Numerical heat transfer and fluid flow, 1980, Mc Graw Hill

[48] Luo J.Y., Issa R.I., Gosman A.D., Prediction of Impeller Induced Flows in Mixing Vessels Using Multiple Frames of Reference, IChemE Symposium Series, 1994, 136, 549-556

[49] Armenante P. M., Chou C.C., Velocity profiles in a baffled vessel with single or double pitched- blade turbines, A.I.ch.E.J., 1997, 42, 42-54

[50] Akiti O., Armenante P.M., Experimentally-validated micromixing based CFD model for fed-batch stirred reactor, Alch.E.Journal., 2004, 56, 566-577 